\title{
Profiling of User Satisfaction Level toward Ciputra Information System (CIS)
}

\section{Damelina Basauli Tambunan and Steve Siebert}

Magister Management Program, Universitas Ciputra, Surabaya, Jawa Timur, Indonesia

\begin{abstract}
This study aims to determine the average level of user satisfaction toward an information system named Ciputra Information System (CIS) which used by Universitas Ciputra on daily basis. There five dimensions used in this study to measure the satisfaction level of users toward CIS; which is Competence of e-Service Support Staff, System availability, Service Portfolio, Responsiveness, and Reliability. The analytical tool used in this study is descriptive statistics and supported by phenomenology. The population in this study are clustered in three group; they are students, lecturers, and operational staffs. The cluster sampling method are used for the clustered population to obtain the statistics data through the questionnaire. The level of satisfaction for each sample group is 3.99 for students, 3,705 for lecturers, and 3,838 for non-lecturer staff with an overall average score of 3,844. There are only two factors that get an average above 4,0; namely Competence of e-Service Support Staff and System availability.
\end{abstract}

Corresponding Author: Damelina Basauli Tambunan damelina@ciputra.ac.id

Received: 30 December 2019 Accepted: 29 January 2020 Published: 6 February 2020 Publishing services provided by Knowledge E

(c) Damelina Basauli Tambunan and Steve Siebert. This article is distributed under the terms of the Creative Commons Attribution License, which permits unrestricted use and redistribution provided that the original author and source are credited.

Selection and Peer-review under the responsibility of the 6 th ICOEN 2019 Conference Committee.
S OPEN ACCESS
Keywords: Satisfaction Level, Information System (IS), IS Performance

\section{Introduction}

Universitas Ciputra (UC) is one of the leading university in creating entrepreneurs uses a system called Ciputra Information System or CIS for short. As we all know, educational institutions need to have information systems in order to improve individual and organizational performance [1]. For that purpose, Universitas Ciputra need to measure its CIS to find out how well the system perceived by its stakeholders. To do that, it needs to understand actions and roles not separating action from research. One of the practice of action research is to identified that the understanding of roles, actions and interaction can help handle dilemmas in action research [2].

This research adapted the Information System (IS) success model proposed by DeLone and McLean [3] which argues that system quality and information quality affect usage and user satisfaction, both of which further lead to individual impact and organizational impact. Later, they and included service quality into the model [4, 5]. The IS success model has been widely used to examined the adoption of various IS [i.e. 6 , 
7, 8]. There are 5 factors that are measured to find out the level of satisfaction of this CIS namely competence of e-service support staff' system availability, service portfolio, responsiveness and reliability. Each of these five factors explain briefly as follows.

Competence of e-service support staff describes the ability and knowledge of eservices that are used to help or guide users through the steps of using e-service, as well as the ability to explain the functions of an available feature, to the ability to listen and respond the needs of customers who are experiencing difficulties in a way that is easily understood by the user. And then the System availability discusses the availability of the system in providing the features needed by the customer before making transactions until the transaction process is completed with all the data requirements and with a smooth running process with limitations such as internet connections or power outages. Next the service portfolio explains a collection of data about IS. Data such as achievements or awards, security level, etc. The better a portfolio of e-services, the higher the level of user confidence in the e-service and the higher the chance of the system being used by the user. Responsiveness illustrates the speed of information systems to respond the user needs during the transaction process. The faster the IS response to user needs, the better the assessment and user satisfaction. And last, Reliability is judged by how reliable the IS provides data and conduct transactions that the user needs. The higher the level of accuracy, security, and speed of the processes carried out, the higher the level of reliability that is owned by the user of the IS used.

Performance measurement of a service system necessitates measurement information from three perspectives: the performance of individual actors, the internal efficiency of a network and the customer-perceived performance of service operation [9]. According to Ayo, Oye and Adewoye (2016) [10] perceived e-service quality has a strong influence on customer satisfaction and use of e-banking which means that greater quality of e-service has the potential to increase satisfaction and consequently result in to more use of e-banking. Therefore, this research will measure the level of satisfaction of three groups of users; they are students, operational staff and lecturers on the information system developed, namely CIS using five factors which is e-service support staff' system availability, service portfolio, responsiveness and reliability.

\section{Methods and Equipment}

\subsection{Methods}




\subsubsection{Diagrammatic representation}

The research is conducted using descriptive statistics and phenomenology as shown in Figure 1. The sample for this research is taken from three out of five user categories which is the student (98), lecturer (60), and operational staff (61). The other two user categories which is the prospective student and alumni are not used because they very rarely used the system. The data are gathered through online questionnaire with the help of Google form since February to April 2018.

For the phenomenology, the data are collected from the one of the author's experience as one of the team member in developing CIS. The data are collected with three steps that starts with description of precociousness where the subject consciously understand what is happening and able to explain them; then followed by reduction of consciousness where the data are selected based on the importance; and end with interpretation of experience where the selected data are interpreted [11].

The research data which gathered from this two method then combined to complement each other and give the result better interpretation of the result, and help Universitas Ciputra to better understand the good and the bad of CIS in hope to improve the services and benefit for both; Universitas Ciputra and the users.

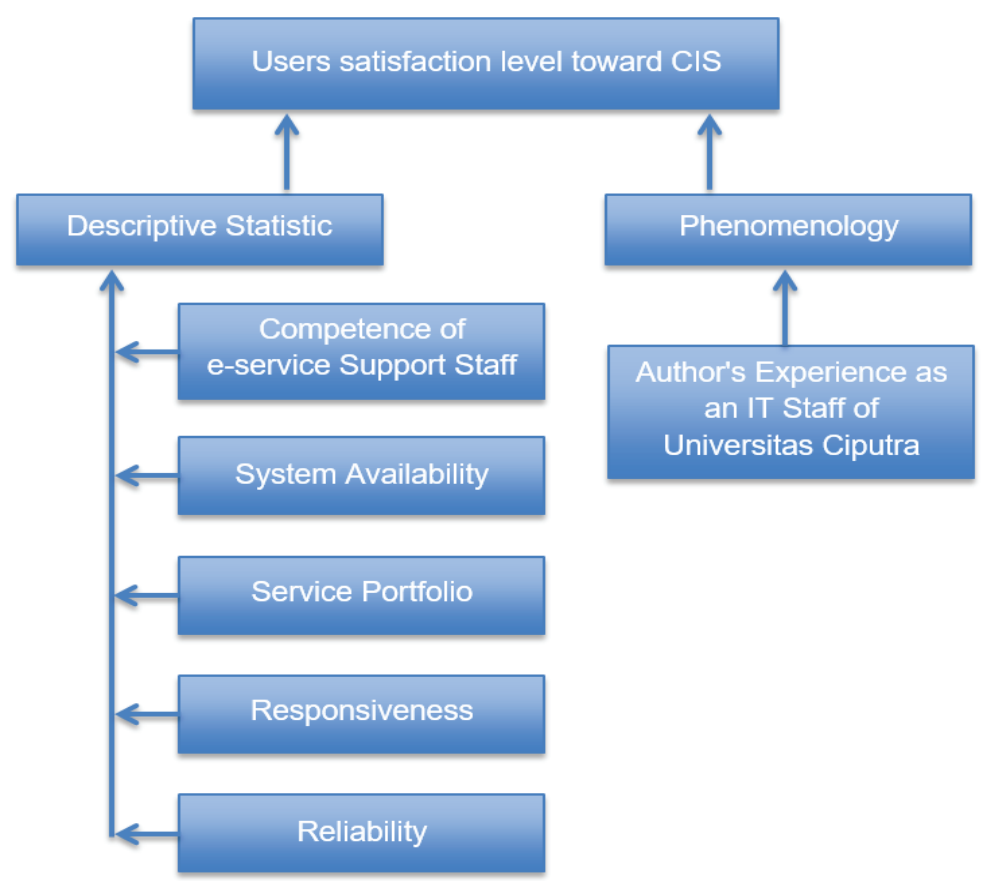

Figure 1: The proposed research model. 


\section{Results}

The result from the descriptive statistic that show in table 1 shown that the average level of users satisfaction toward CIS's performance 3.844 (students 3.99; lecturers 3.705; operational staffs 3.838). From the five factors used in this study, only competence of e-service support staff and system availability manage to get result above 4 .

The phenomenology indicating that $\mathrm{CIS}$ as a new information system and still in growing stage does not really has a good reputation which make the users expectation not too high. Although the software is still quite new, the support staff are quite experienced. Since the support staff are experienced, some service failure has been covered. The new software are still adjusting to the new server environment in the cloud which make the configuration and the stability are quite unstable. Because of the recent instability and the growing phase, although the new software become more available for using the cloud services, the reliability and responsiveness are reduced. The instability are not entirely from the software or the server, the users connection also become another factor. This is a phase where the system are still trying to adapt to the new environment and the keep growing feature.

The descriptive statistics and the phenomenology are actually very align. The service portfolio are not that good because most users understand what is currently happening with the system; the service from support staff are good because they are experience; the system availability is good because of the cloud services recently used by the system; responsiveness and reliability are quite on the lower side because of the change of the system environment.

\section{Discussion}

The results indicate that CIS still need to be improved especially 2 factors which is responsiveness and reliability of the system, since these two factors is the lowest average among all the group of users and overall users. On the other hand, the result in service portfolio indicate that CIS's reputation might not that far from the users expectation. Out of five factor that used in this research three of them are directly related to the used technology; and only one manage to get a result above four. This indicate that CIS need to be improved further.

This research succeeded in showing that the level of user satisfaction is below an average of 4.0 which is 3.84 on a scale of $1-5$ which means it is not satisfied. This shows the need to increase the level of satisfaction with various efforts. The proposed effort 
TABLE 1: Descriptive Statistics.

\begin{tabular}{|c|c|c|c|c|}
\hline Category & Factor & Cronbach's $\alpha$ & Mean & $\begin{array}{l}\text { Standard } \\
\text { deviation }\end{array}$ \\
\hline \multirow[t]{6}{*}{ Student } & $\begin{array}{l}\text { Competence of } \\
\text { e-Service Support Staff }\end{array}$ & 0.957 & 3.84 & 0.915 \\
\hline & System availability & 0.839 & 4.33 & 0.664 \\
\hline & Service Portfolio & 0.642 & 4.21 & 0.779 \\
\hline & Responsiveness & 0.699 & 3.66 & 0.984 \\
\hline & Reliability & 0.761 & 3.91 & 0.836 \\
\hline & Overall & & 3.99 & 0.836 \\
\hline \multirow[t]{6}{*}{ Lecturer } & $\begin{array}{l}\text { Competence of } \\
\text { e-Service Support Staff }\end{array}$ & 0.903 & 4.163 & 0.6010 \\
\hline & System availability & 0.770 & 3.771 & 0.8689 \\
\hline & Service Portfolio & 0.832 & 3.397 & 0.9463 \\
\hline & Responsiveness & 0.815 & 3.550 & 0.8451 \\
\hline & Reliability & 0.781 & 3.644 & 0.8673 \\
\hline & Overall & & 3.705 & 0.8257 \\
\hline \multirow[t]{6}{*}{ Operational Staff } & $\begin{array}{l}\text { Competence of } \\
\text { e-Service Support Staff }\end{array}$ & 0.958 & 4.197 & 0.8134 \\
\hline & System availability & 0.806 & 4.098 & 0.9155 \\
\hline & Service Portfolio & 0.705 & 3.934 & 0.8813 \\
\hline & Responsiveness & 0.889 & 3.601 & 0.9849 \\
\hline & Reliability & 0.852 & 3.358 & 0.8939 \\
\hline & Overall & & 3.838 & 0.8978 \\
\hline \multirow[t]{6}{*}{ Overall } & $\begin{array}{l}\text { Competence of } \\
\text { e-Service Support Staff }\end{array}$ & & 4.067 & \\
\hline & System availability & & 4.066 & \\
\hline & Service Portfolio & & 3.847 & \\
\hline & Responsiveness & & 3.604 & \\
\hline & Reliability & & 3.637 & \\
\hline & Overall & & 3.844 & \\
\hline
\end{tabular}

is to make a CIS usage manual given to all users. This will guide the user in using CIS. this method will certainly be cheaper and more efficient, so users do not have to meet staff when experiencing problems. The findings that indicate that the highest level of satisfaction is in the Competence of e-Service Support Staff factor, means that the high need for users to be guided when using the application, but due to the limited number of staff support available, makes the idea of making a manual book realistic. 
The level of satisfaction in responsiveness was found to be the lowest at 3,637 . One statement that was asked about the Responsiveness factor was an understanding of the menus available in the CIS. The statement presented in questionnaire is "I understand the menu that I must choose when using CIS". Another statement is "If there is a new feature in CIS, I can use it without anyone's help". This means, the need to provide a manual that helps users understand a system easier. In the development of IS, responsiveness is often a factor that causes a lack of level of user satisfaction, as in research conducted by Yuen \& Tahi (2015) where the value of responsiveness factors is the lowest value [12]

The Competence of e-Service Support Staff Factor is the highest factor in overall user satisfaction and in two user groups, namely operational staff and lecturers, whereas in student groups it is not. This is allegedly because the complexity of the menu on students is not too high so the expected support from support staff is less important. The finding that the Competence of e-Service Support Staff factor is the highest satisfaction factor is in line with the findings made by Ayo, et al (2016) [10]. This means that interaction between humans remains an important thing in the era of information technology development. Even though the work system can be handled, the meeting of humans in solving the problems they face becomes more important. Therefore, in the development of applications aimed at automation it must still pay attention to the human touch side. For example, in a system that develops a service center that is served by an automatic answering machine, it is a good idea that the machine is still given a human name, so that when a user submits a problem through the contact menu, the system still gives the impression that the user who is asking is being served by another human being. In addition, when the staff in charge actually serves users who are having problems with IS, it is recommended that supporting staff be trained so that they are truly able to communicate well and humanely so that users feel helped to resolve the problem, thus the level of satisfaction can be increased. As stated in the research of Atyang, Gathumbi \& Babusa (2018), one of the factors that influence the successful use of technology in teaching and learning is the existence of technical support. [13].

Another finding obtained is that the more types of menus the user uses in an IS, the higher the chance of dissatisfaction. As found in this study, the user group, namely students, is the most satisfied group with a satisfaction level of 3.99. The number of menus accessed by this group in the CIS is about 50 menu choices with choices around lecture activities including filling out study plans at the beginning of each semester, viewing grades, attendance, menu facilities such as announcements, libraries, improvement boxes and other items. Furthermore, the second highest satisfaction group 
is the staff group with a satisfaction value of 3,838 and the menu available for them to access is around 200 covering work-related services (eg financial requests, requests for use of space and equipment) to services related to roles as an employee for example requests for leave, enter work-related documents, see attendance and so forth. The group with the lowest level of satisfaction is lecturers with an average value of 3.705 with menus that can be accessed around 250 people consisting of 3 groups, namely menus related to work such as lecture material input, entering work documentation, input exam questions, grades, student attendance and so forth. The second menu is a group of menus related to human capital services such as leave request services, health claims, etc. and third is a menu of facilities such as libraries, documents available and so on. This gives meaning, that in the development of an IS, it is necessary to attempt to simplify the user's work in input by synchronizing multiple transactions to one transaction simply because it synchronizes directly on one menu or a different menu. That is, when the user makes one transaction, the system automatically synchronizes with other related menus. For example when a lecturer inputs participation in an event (fills in the leaving office menu) and uploads a certificate obtained from the event, it automatically synchronizes with the lecturer participation report menu at an event. In general, what usually happens is that the user has to make 2 transactions, which is to fill in leaving office transaction and fill in a competency improvement activity transaction. If 2 transactions can be input once, it will certainly make it easier for the lecturer, so they do not feel that there are too many input activities carried out by a lecturer. This is in accordance with what was found by [14], that selection of the IS is a critical decision making task that can significantly impact operational excellence and competitive advantage of modern enterprise.

\section{Conclusion}

This study found that of the five factors that measure the level of satisfaction of CIS users only 2 factors have an average value above 4.0, namely Competence of eService Support Staff and System availability. Other factors, namely service portfolio, responsiveness and reliability have an average value below 4.0. Of the three user groups, users with fewer CIS menus, namely the student user group, had the highest satisfaction while the user with the most menu choices which is the user lecturer group had the lowest level of satisfaction. 


\section{Acknowledgement}

The authors would like to thank Universitas Ciputra for giving opportunity to distribute the questionnaire to the students, operational staff and lecturers.

\section{Conflict of Interest}

The authors have no conflict of interest to declare.

\section{References}

[1] Ahmed, A. A., Abu-Naser, S. S., El Talla, S. A., \& Al Shobaki, M. J. (2018). The Impact of Information Technology Used on the Nature of Administrators Work at Al-Azhar University in Gaza.

[2] Melin, U., \& Axelsson, K. (2016). Action in action research. Journal of Systems and Information Technology, 18(2), 118-147. doi:10.1108/jsit-10-2015-0074.

[3] DeLone, W.H. and McLean, E.R. (1992). Information systems success: the quest for the dependent variable. Information Systems Research, Vol. 3 No. 1, pp. 60-95.

[4] DeLone, W.H. and McLean, E.R. (2003). The DeLone and McLean model of information systems success: a ten-year update. Journal of Management Information Systems, Vol. 19 No. 4, pp. 9-30.

[5] Gao, L., \& Bai, X. (2014). An empirical study on continuance intention of mobile social networking services. Asia Pacific Journal of Marketing and Logistics, 26(2), 168-189. doi:10.1108/apjml-07-2013-0086.

[6] Chaveesuk, S., Wutthirong, P., \& Chaiyasoonthorn, W. (2018). The Model of Mobile Payment System Acceptance on Social Networks in Thailand: A Conceptual Framework. In Proceedings of the $201810^{\text {th }}$ International Conference on Information Management and Engineering. (pp. 35-39). ACM.

[7] Teo, T. (2009). Evaluating the Intention to Use Technology among Student Teachers: A Structural Equation Modeling Approach. International Journal of Technology in Teaching \& Learning, 5(2).

[8] Martinc, M., Skrjanec, I., Zupan, K., \& Pollak, S. (2017). PAN 2017: Author ProfilingGender and Language Variety Prediction. In CLEF (Working Notes).

[9] Laihonen, H., Jääskeläinen, A., \& Pekkola, S. (2014). Measuring performance of a service system -- from organizations to customer-perceived performance. Measuring Business Excellence,18(3), 73-86. doi:10.1108/mbe-08-2013-0045. 
[10] Ayo, C. K., Oni, A. A., Adewoye, O. J., \& Eweoya, I. O. (2016). E-banking users' behaviour: e-service quality, attitude, and customer satisfaction. International Journal of Bank Marketing, 34(3), 347-367. doi:10.1108/ijbm-12-2014-0175.

[11] Lanigan, R. L. (2015). Human embodiment. Metodo. International Studies in Phenomenology and Philosophy, 3.1(1), 257-287. doi:10.19079/metodo.3.1.257

[12] Yuen, K. F., \& Thai, V. V. (2015). Service quality and customer satisfaction in liner shipping. International Journal of Quality and Service Sciences, 7(2/3), 170-183. doi:10.1108/ijqss-02-2015-0024.

[13] Atyang, F., Gathumbi, A., \& Babusa, H. (2018). School Management and Technical Support to Teachers and Students in the Integration of ICT in Teaching/Learning English Language. Advances in Social Sciences Research Journal, 5(7).

[14] Toloo, M., Nalchigar, S., \& Sohrabi, B. (2018). Selecting most efficient information system projects in presence of user subjective opinions: a DEA approach. Central European Journal of Operations Research, 26(4), 1027-1051 